\title{
Recycling of three different types of rural wastes employing vermicomposting technology by Eisenia fetida at low temperature
}

\author{
Seyyed Alireza Mousavi ${ }^{1}$, Majid Faraji2, ${ }^{*}$ and Hosna Janjani ${ }^{3}$ \\ ${ }^{1}$ Department of Environmental Health Engineering, and Research Center for Environmental Determinants of Health (RCEDH), Faculty of \\ Health, Kermanshah University of Medical Sciences, Kermanshah, Iran \\ ${ }^{2}$ Department of Environmental Health Engineering, Kermanshah University of Medical Sciences, Kermanshah, Iran \\ ${ }^{3}$ Department of Environmental Health Engineering, Faculty of Health, Kermanshah University of Medical Sciences, Kermanshah, Iran \\ Received: 02/02/2017, Accepted: 19/04/2017, Available online: 22/11/2017 \\ *to whom all correspondence should be addressed: e-mail: majeadfaraji@yahoo.com
}

\begin{abstract}
This study was conducted to investigate the recycling of rural wastes employing vermicomposting technology by Eisenia fetida. Three medium including kitchen waste, rotting foliage and cow dung were performed in 20 treatments. Results showed that in all 20 treatments the quality of produced compost was in the standard range. Due to the high levels of nitrogen in raw material of some treatments, (e.g. treatments that percentage of cow dung and kitchen waste are zero such as $\mathrm{M}, \mathrm{N}, \mathrm{O}, \mathrm{Q}, \mathrm{R}$ and $\mathrm{U}$ ) the concentration of $\mathrm{N}$ in mature compost was higher than other treatments. The type of raw material in the medium has particular importance on the quality of compost. So that any change in the composition due to changes in the presence or absence of macro and micronutrients can influence the compost production process and reproduction of worm. Therefore, optimization of medium components, as shown in this study is of specific importance that has effect on the vermicomposting at low temperature.
\end{abstract}

Keywords: Waste; Cow dung; Vermicompost; Eisenia fetida; Compost quality.

\section{Introduction}

A major issue facing world wide countries that has been and will continue to be, is municipal solid waste management. And in developing countries is more important, because the total amount of municipal solid waste has increased dramatically due to increasing urban population and rapid industrialization (Chen et al., 2010; Pokhrel and Viraraghavan). As all components of the environment and human health can be affected by untechnical disposal of wastes (Sharholy et al., 2008). So, the environmentally acceptable management of municipal solid waste has become a global priority (Pokhrel and Viraraghavan, 2005).

Because organic material makes up a large part of the waste in Iran, so appropriate alternative for the safe, hygienic and cost-effective disposal of waste is vermicomposting (Kaviraj and Sharma, 2003). A good way to minimize the health and environmental impact of waste is composting that can return some of the costs of waste management. As the vermicompost contain more valuable products, so it is an important difference between vermicomposting, composting and other methods of waste disposal (Garg et al., 2006). In process of vermicomposting microbes do the biochemical degradation of organic matter and earthworm acts as mechanical blenders, by comminuting the organic matter; they modify its biological, physical and chemical quality, gradually increasing the surface area exposed to microorganisms and reducing its $\mathrm{C}: \mathrm{N}$ ratio (Yadav and Garg, 2011).The epigeic earth worm Eisenia fetida because of its rapid growth rate, early sexual maturity and extensive reproduction, has been extensively used to produce vermicompost from different plant residues, city refuse and sewage sludge (Devi et al., 2012). In weather conditions of Iran, Eisenia fetida is more efficient (Jicong et al.,2005).

Producing vermin compost are affected by various parameters such as temperature, moisture, $\mathrm{pH}$, the ratio of carbon to nitrogen, air, food source, light and medium (Gheisari et al., 2009).Several studies have been conducted in this field by using different medium: Vermicomposting of autumn leaves (Sufyan et al., 2011), recycling sewage sludge and produce vermin compost (Hwairakpam and Bhargava, 2009), vermi compost production of vegetable market waste (Suthar, 2009), and rapid recycling of nutrients from bio-sludge of beverage industry (Singh et al., 2010). Furthermore, in rural areas, animal waste, foliage and kitchen waste with all the values, can be a major contributor to environmental pollution that caused by mismanagement. Since approximately $70-80 \%$ of the solid waste management costs relate to collection and transportation, the conversion of waste at source as a meaningful option should be considered in the waste management in the rural areas. An alternative on the home scale could be Vermicomposting when land restrictions are a concern (Lleó et al., 2013).

In view of the above, the major objective of this study was to investigate the quality of produced vermicompost by applying three medium including kitchen waste, rotting 
foliage and cow dung at different percentage at low degree of temperature.

\section{Material and methods}

\subsection{Experimental setup}

The experiments were conducted in polyethylene containers with total volume of $5 \mathrm{~L}$, each containing $0.5 \mathrm{~kg}$ waste, with mesh bottom. Each container, having a size of $25 \mathrm{~cm}, 30 \mathrm{~cm}$ and $20 \mathrm{~cm}$ (length, width and height) that was consisted of two layers: a substrate layer, and a leachate collecting layer. Eisenia fetida was obtained from a vermicompost site in Sahnah City, Kermanshah, where it has been cultured for the last 2 years and identified by research center of agriculture Faculty. The organic waste used as substrate, was collected from the rural area in Kermanshah city. To provide an initial favorable environmental condition for the worms (E. fetida), the kitchen waste was pre-decomposed by aeration through air pump to prevent anaerobic condition for 20 days. After that medium composition including kitchen waste, rotting foliage and cow dung at the different percentage mixed according to Table 1 , were stored in a dark room at $25 \pm 2{ }^{\circ} \mathrm{C}$ and its moisture was kept at approximate $70 \%$ by sprinkling with water for 7 days. A total of 20 treatments with 2 replicas for each treatment have been used in this research work that ten earthworms of the same size were introduced in each of pots. Moisture content was maintained between $60 \%$ and $70 \%$ during the experiments (90 days).

Table 1. The composition of waste mixtures (\%) in vermicomposting units

\begin{tabular}{|c|c|c|c|c|c|c|c|}
\hline $\begin{array}{l}\text { Samples } \\
\text { number }\end{array}$ & $\begin{array}{c}\text { Food } \\
\text { Wastes }\end{array}$ & Foliage & Cow dung & $\begin{array}{l}\text { Samples } \\
\text { number }\end{array}$ & $\begin{array}{l}\text { Food } \\
\text { waste }\end{array}$ & Foliage & Cow dung \\
\hline A & 20 & 10 & 70 & B & 40 & 10 & 50 \\
\hline C & 60 & 10 & 30 & D & 80 & 10 & 10 \\
\hline$E$ & 100 & 0 & 0 & $\mathbf{F}$ & 20 & 30 & 50 \\
\hline G & 40 & 30 & 30 & $\mathrm{H}$ & 60 & 30 & 10 \\
\hline$I$ & 20 & 50 & 30 & $\mathrm{~J}$ & 40 & 50 & 10 \\
\hline $\mathrm{K}$ & 90 & 10 & 0 & $\mathbf{L}$ & 70 & 20 & 0 \\
\hline$M$ & 50 & 50 & 0 & $\mathbf{N}$ & 30 & 70 & 0 \\
\hline 0 & 10 & 90 & 0 & $\mathbf{P}$ & 0 & 10 & 90 \\
\hline$S$ & 0 & 30 & 70 & $\mathbf{Q}$ & 0 & 50 & 50 \\
\hline $\mathbf{R}$ & 0 & 70 & 30 & $U$ & 0 & 90 & 10 \\
\hline
\end{tabular}

\subsection{Sampling and Chemical analysis}

To have a homogenous samples, the medium divided into three equal parts and one sample was selected in each part. The samples were mixed together and after ground, samples were selected from the obtained powder. The physico-chemical analysis was done on dry weight basis. The analysis of raw organic waste and vermicompost samples, was done for total kjeldhal nitrogen (TKN), total $P$, total organic carbon (TOC), total sodium (Na), total potassium(K), $\mathrm{pH}$, electrical conductivity( $\mathrm{EC})$ and moisture. The organic matter and ash were measured by thermal method (weight reduction) using electric furnace, (Nabertherm, US). TKN was measured by Micro-Kjeldhal method of Bremner and Mulvaney (1982) after digesting the sample in digestion mixture $\left(\mathrm{H}_{2} \mathrm{SO}_{4}+\mathrm{K}_{2}-\mathrm{SO}_{4}: \mathrm{CuSO}_{4}: \mathrm{SeO}_{2}\right.$ in 10:4:1) (Bremner and Mulvaney, 1982). Total available phosphate was analyzed by using the spectrophotometric method with molybdenum in sulphuric acid. Total organic carbon was measured by using the method provided by Nelson and Sommers (1996). Total potassium and total sodium were determined by flame photometer (Jenway, England), after digesting the samples in diacid mixture. The $\mathrm{pH}$ and electrical conductivity (EC) were determined using a double distilled water suspension of each sample in the ratio of 1:10 (w/v) using (EDT, England and WTW, Germany). The moisture was determined by gravimetric method

\subsection{Statistical analysis}

SPSS software version 22 and Excel 2016 have been used to data analysis. To minimize the analysis error three replicates for all tests have been considered during experiments. All the reported data are the means of three replicates. Kruskal-Wallis test was done to determine any significant difference between the numbers and weights of earthworms.

\section{Results and discussion}

Figure1 demonstrated data pertaining to $\mathrm{C}: \mathrm{N}$ ratio. The initial C:N ratio of wastes according to Table 2 at the same portion was 37.24 and data revealed a significant difference in percentage decrease of the TC in all 20 treatments. Reduction in $\mathrm{C} / \mathrm{N}$ ratio reflects the relative stability of vermicompost and the progress of humus. Kruskal-Wallis test (Fisher F-test) showed that although the average ratio of $\mathrm{C} / \mathrm{N}$ on different medium are not the same but there is a significant correlation $(P<0.000)$ between type and percentage of medium used in each treatment with $\mathrm{C} / \mathrm{N}$ ratio. Most of the $\mathrm{C} / \mathrm{N}$ ratio related to the $\mathrm{D}, \mathrm{E}, \mathrm{K}$ and I treatments that kitchen wastes were formed most substrate materials. The results of present study are supported by previous research works. Bansal S, and Kapoor K.K (2000) produced vermicompost from mixture of crop residues and cattle dung using Eisenia fetida. Their results confirmed reduction of the $\mathrm{C} / \mathrm{N}$ ratio at the end of process (Bansal and Kapoor, 2000). Elvira et al., (1998) 
revealed that $20-42 \%$ of carbon as $\mathrm{CO}_{2}$ during vermicomposting of paper mill and dairy sludge had reduced (Elvira et al., 1998).

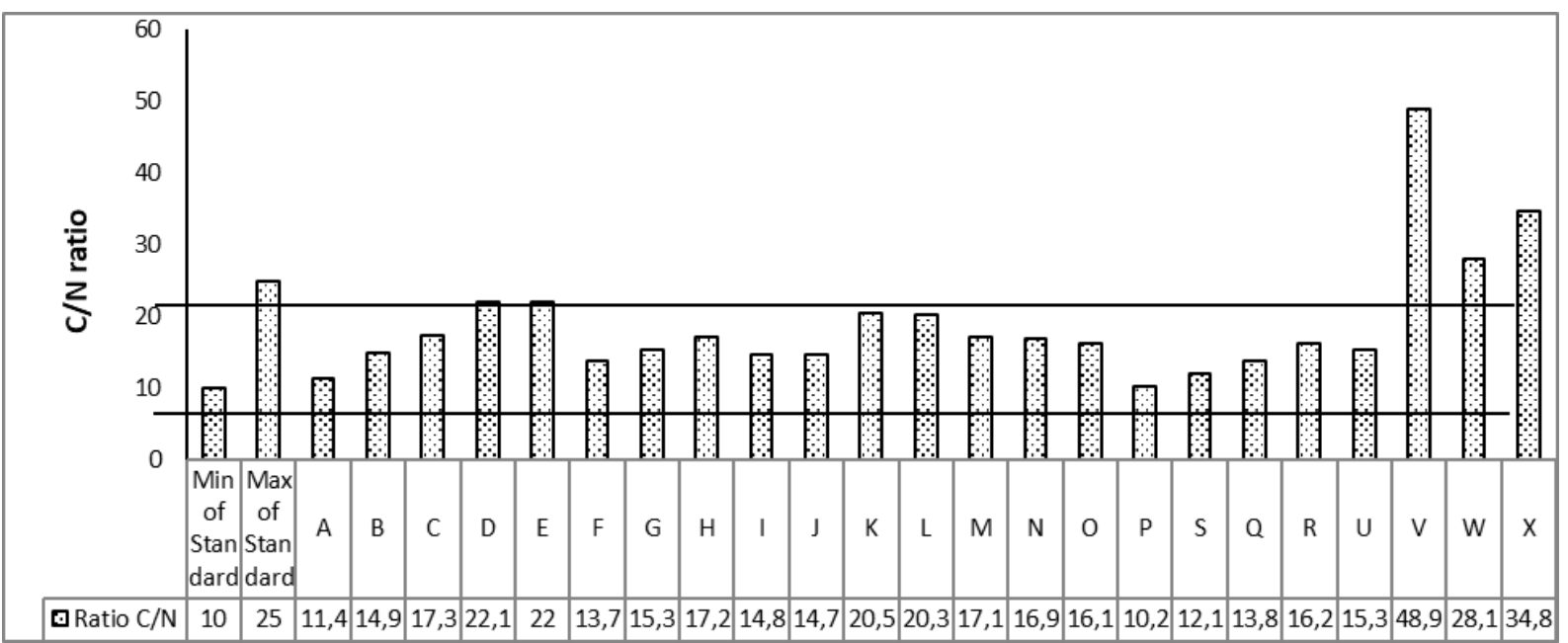

Figure 1. $\mathrm{C} / \mathrm{N}$ ratio of vermicompost treatments compared to standard values ( $\mathrm{V}=$ Food wastes; $\mathrm{W}=$ Foliage; $\mathrm{X}=\mathrm{Cow}$ dung)

Table 2. Initial physico-chemical characteristics of Food Wastes (FW), Rotting Foliage(RF), Cow Dung(CD)

\begin{tabular}{cccc}
\hline Parameter & FW & RF & CD \\
\hline \%Ash & 7.88 & 57.7 & 36.4 \\
\hline \%TN & 0.97 & 1.03 & 0.92 \\
\hline$\% \mathrm{~K}$ & 4.23 & 0.96 & 1.92 \\
\hline$\% \mathrm{Na}$ & 6.49 & 0.91 & 2.42 \\
\hline$\% \mathrm{TOC}$ & 47.43 & 28.91 & 32 \\
\hline $\mathrm{C} / \mathrm{N}$ & 48.9 & 28.06 & 34.78 \\
\hline$\% \mathrm{Tp}$ & 1.43 & 0.95 & 0.82 \\
\hline $\mathrm{Ec}(\mu \mathrm{s} / \mathrm{cm})$ & 9670 & 6500 & 7140 \\
\hline $\mathrm{pH}$ & 5.2 & 7.9 & 6.34 \\
\hline
\end{tabular}

Table 3 summarizes data pertaining to other parameters namely; TOC, TN, TP, Na, K, pH, EC and moisture. After 90 days carbon content of all treatments has dropped in comparison the baseline. The results showed that the greatest amount of TOC was in $M, N, R, O$ and $U$ samples. In A, S, P and $F$ samples that animal wastes have formed a higher percentage of raw materials, more reduction in TOC of treatments has been observed. While reducing TOC were less in $E, K, L$ and $D$ samples, which contain more food. The amount of TOC in the $\mathrm{M}, \mathrm{U}, \mathrm{N}$ and $\mathrm{O}$ samples that foliage makes up a higher percentage of raw materials, respectively were $35.89 \%, 32.2 \%, 35.5 \%$ and $33.87 \%$. The results of Kruskal-Wallis analysis (Fisher F-test) showed a significant correlation $(P<0.000)$ between type and percentage of medium used in each treatment with TOC changes. TOC of all treatments have dropped due to mineralization of the organic matter and the release of part of the organic carbon into carbon dioxide in the process of microbial degradation of the substrate material. The results are in accordance with previous results of vermicomposting of different types of tanning sludge (liming and primary) mixed with cattle dung and vermicomposting of vegetable waste (Malafaiaa et al., 2015; Suthar, 2009).

According to Table 3 in all vermicomposts units' significant increase in $\mathrm{N}$ concentration occurred at the end of the experiment. The TN content of the waste mixtures and single waste ranged from $0.97 \%$ and $0.92 \%$ (cow dung), $0.97 \%$ (food waste) and $1.03 \%$ (foliage), respectively. The amount of TN of produced vermicomposts was in range of $0.99 \%$ to $2.14 \%$. The TN content showed about $0.99 \%$ (vermicomposting unit $\mathrm{L}$ ) to 2.14 (vermicomposting unit $\mathrm{R}$ ), which 2.16-fold increase as compared to initial waste mixtures. Statistical analysis of results showed a significant correlation $(P<0.004)$ between type and percentage of medium used in each treatment with $\mathrm{N}$ changes. However, increase of TN happened in all units but the greatest increase occurred in vermicomposting units of $M, N, O, Q$, $\mathrm{R}$ and $\mathrm{U}$ when foliage formed more raw materials (above $50 \%)$ of substrate. The lowest nitrogen content also related to $D, E, L$ and $K$ treatments that the food was formed most of the raw materials. This nitrogen increase can be attributed to the loss of organic carbon, reduction in $\mathrm{pH}$, mineralization of organic compounds containing proteins and conversion of ammonium nitrogen to nitrate. In study of effects of earthworms on physicochemical properties and microbial profiles during vermicomposting of fresh fruit and vegetable wastes, total nitrogen content increased during the first 2 weeks and then followed by a progressive decrease to the end and the progressive decrease of total nitrogen in the vermicomposting system was probably linked to the loss of substantial nutrients in the form of leachate, (Huang et al., 2014), the results are in accordance with previous studies(Adi and Noor, 2009; Garg et al., 2006). This result is achievable due to the degradation of the labile organic compounds, which is cause of the volume of the composting mass due to release of $\mathrm{CO}_{2}$ and the mineralization of nitrogen during decomposition of organic matter resulting in increased total $\mathrm{N}$ in the vermicompost (Malafaiaa et al., 2015).

The $\mathrm{pH}$ value of waste materials to prepare vermicompost significantly influences the process. The results pointed out that samples contain more food waste have been changed in order to increase the $\mathrm{pH}$, because $\mathrm{pH}$ was lower than other raw materials (Table 2). Low $\mathrm{pH}$ of food waste 
resulting from the production of $\mathrm{CO}_{2}$ and organic acids from microbial degradation in the aeration stage (Elvira et al., 1998). While $\mathrm{pH}$ changes were low in samples with more percent of animal waste or foliage. Kruskal-Wallis test (Fisher F-test) analysis results showed a significant correlation $(P<0.000)$ between type and percentage of medium used in each treatment with $\mathrm{pH}$ changes. Results are in accordance with results of previous studies (Garg et al., 2006; Suthar \& Singh, 2008).

Table 3. Physico-chemical characteristics of initial waste mixtures and vermicomposts (mean \pm SD, repetition $=3$ ).

\begin{tabular}{|c|c|c|c|c|c|c|c|c|c|c|c|}
\hline $\begin{array}{l}\text { Variables } \\
\text { samples }\end{array}$ & $\begin{array}{l}\text { Number } \\
\text { of worms }\end{array}$ & $\begin{array}{c}\text { Weight } \\
\text { worms } \\
\text { (g) }\end{array}$ & $\begin{array}{c}\text { Ash } \\
\%\end{array}$ & $\begin{array}{l}\mathrm{TN} \\
\%\end{array}$ & $\begin{array}{l}K \\
\%\end{array}$ & $\begin{array}{c}\mathrm{Na} \\
\%\end{array}$ & $\begin{array}{c}\text { TOC } \\
\%\end{array}$ & $\begin{array}{l}\text { Tp } \\
\%\end{array}$ & $\begin{array}{c}\text { Organic } \\
\text { material } \\
\% \\
\end{array}$ & $\begin{array}{c}\text { Ec } \\
\mu \mathrm{s} / \mathrm{cm}\end{array}$ & $\mathrm{pH}$ \\
\hline$A$ & 62 & 34.40 & 53.51 & 1.54 & 1.20 & 2.45 & 17.5 & 0.53 & 46.29 & 3142 & 8.38 \\
\hline$B$ & 50 & 28.40 & 35.57 & 1.43 & 1.12 & 1.80 & 21.36 & 1.52 & 64.43 & 3950 & 8.15 \\
\hline$C$ & 40 & 21.05 & 48.85 & 1.47 & 2.14 & 2.59 & 25.40 & 1.90 & 58.15 & 5340 & 7.39 \\
\hline $\mathrm{D}$ & 23 & 13.45 & 16.58 & 1.1 & 2.62 & 2.90 & 24.3 & 2.52 & 83.42 & 8169 & 7.54 \\
\hline$E$ & 20 & 13.41 & 13.77 & 1.1 & 2.5 & 3.02 & 24.2 & 2.83 & 86.83 & 8940 & 6.95 \\
\hline $\mathrm{F}$ & 75 & 22.40 & 66.38 & 1.23 & 1.5 & 2.50 & 16.83 & 0.85 & 33.62 & 3640 & 7.45 \\
\hline $\mathrm{G}$ & 40 & 25.12 & 41.18 & 1.40 & 1.19 & 1.90 & 21.43 & 1.62 & 58.82 & 4510 & 7.18 \\
\hline $\mathrm{H}$ & 31 & 16.22 & 42.8 & 1.46 & 2.25 & 2.49 & 25.12 & 1.98 & 57.30 & 5390 & 6.66 \\
\hline 1 & 42 & 21.80 & 49.19 & 1.45 & 1.14 & 1.72 & 21.43 & 1.10 & 50.81 & 4520 & 7.46 \\
\hline $\mathrm{J}$ & 31 & 16.32 & 47.32 & 1.49 & 1.36 & 1.75 & 21.90 & 1.14 & 52.68 & 4630 & 8.10 \\
\hline $\mathrm{K}$ & 27 & 13.52 & 15.09 & 1.12 & 2.32 & 2.89 & 22.9 & 2.62 & 84.91 & 8420 & 7.64 \\
\hline $\mathrm{L}$ & 27 & 11.48 & 17.9 & 0.99 & 2.10 & 2.65 & 20.1 & 1.93 & 82.10 & 8100 & 7.07 \\
\hline$M$ & 61 & 15.40 & 47.51 & 2.1 & 1.14 & 2.90 & 35.89 & 0.72 & 52.49 & 6140 & 7.05 \\
\hline $\mathrm{N}$ & 23 & 11.12 & 49.52 & 2.1 & 0.97 & 2.40 & 35.50 & 0.76 & 50.48 & 4640 & 7.06 \\
\hline 0 & 81 & 15.80 & 55.61 & 2.1 & 0.95 & 1.12 & 33.87 & 1.12 & 44.39 & 4680 & 7.37 \\
\hline $\mathrm{P}$ & 50 & 28.40 & 61.25 & 1.6 & 1.40 & 2.30 & 16.30 & 048 & 38.75 & 2310 & 7.71 \\
\hline$S$ & 63 & 11.67 & 54.88 & 1.42 & 1.25 & 2.45 & 17.21 & 0.55 & 45.12 & 3151 & 7.76 \\
\hline$Q$ & 256 & 90.48 & 65.58 & 1.8 & 1.35 & 2.28 & 24.80 & 0.95 & 34.43 & 3690 & 7.85 \\
\hline $\mathrm{R}$ & 87 & 25.68 & 61.37 & 2.14 & 0.98 & 1.60 & 34.68 & 1.22 & 38.63 & 4869 & 7.88 \\
\hline$U$ & 266 & 89.43 & 66.84 & 2.1 & 0.68 & 1.52 & 32.20 & 0.93 & 33.16 & 4740 & 7.53 \\
\hline
\end{tabular}

The EC reflects the salinity of any material and it is a good indicator of the applicability and utility of a compost or vermicompost for agricultural purposes. The value of EC based on compost duration is different (Majlessi et al., 2012). The EC of vermicompost treatments over 90 days been lower than initial levels. According to the obtained results, the highest EC was $8940 \mu \mathrm{s} / \mathrm{cm}$ and the lowest 2310 $\mu \mathrm{s} / \mathrm{cm}$ that respectively relate to $E$ and $P$ samples. KruskalWallis test (Fisher F-test) analysis results showed a significant correlation $(P<0.000)$ between $E C$ changes with type and percentage of medium used in each treatment. The results also showed the EC of the medium with more food and raw materials ( $D, L, K, E$ samples) has decreased less than the medium with greater amount of animal waste ( $A, S, F, Q$ and $P$ samples). The vermicomposting of primary sewage sludge also showed a decrease in $\mathrm{pH}$, but increase in EC (Gupta and Garg, 2008). Electrical conductivity value in the beginning of the vermicomposting of food waste was $7.5 \mathrm{mS} / \mathrm{cm}$ and in the final product EC reached to 4.9 $\mathrm{mS} / \mathrm{cm}$. It was observed that EC increased between the second to third weeks. The EC increasing related to the release of different mineral ions, such as phosphate, ammonium, potassium etc (Majlessi et al., 2012).

Vermicomposting at a long-time process showed a significant increase in total available phosphorus ( $P$ avail) in different treatment units (Table 3 ). The units $D, E, L$ and $K$ have more increase, that kitchen waste was prominent waste material. The lowest amount of phosphorus relates to medium that animal waste was main substances. Kruskal-Wallis test (Fisher F-test) analysis results showed a significant correlation $(P<0.000)$ between $P$ changes with type and percentage of medium used in each treatment. According to previous studies, the reason for $\mathrm{P}$ increasing associated to raw materials, processing time, quality of materials consumed by worms, the worms, and test conditions (Ndgwa et al., 2000; Hartenstein and Hartenstein, 1981).

Initial concentration of $\mathrm{K}$ in waste was $2.37 \%$ that the level of $\mathrm{K}$ increased in the different treatments units after composting (Table 2). However, there was reduction in the amount of $\mathrm{K}$ in some medium, but this reduction was not significant. The highest amount of $K$ measured in the kitchen waste materials and the least in foliage waste. Kruskal-Wallis test (Fisher F-test) analysis results also between type and percentage of medium used in each treatment with $\mathrm{K}$ changes showed a significant correlation $(P<0.000)$. The results of current study are in accordance with study of vermicomposting from cattle manure (Mitchell, 1997), bagasse and coir (Pramanik, 2010). Bioconversion of garden waste, kitchen waste and cow dung data revealed that total $\mathrm{K}$ have increased significantly higher $(1.01 \pm 0.18)$ in kitchen waste as compared to cow dung $(0.88 \pm 0.18)$ and garden waste $(0.60 \pm 0.02)$ during the study (Wani et al., 2013). Pramanik, (2010) confirmed that during vermicomposting of bagasse and coir the concentration of $\mathrm{K}$ increased about 59-77\%, which 
depending on initial physico-chemical characteristics of wastes.

The amount of $\mathrm{Na}$ in the treatments compared to the raw materials decreased because Earthworms in their internal interactions take sodium. According to result in table 2 Sodium percentage in samples that food waste constituted the largest percentage had more reduction compared to the raw materials ( $H, E, K, L$ and $D$ samples). In samples that foliage waste constituted the largest percentage, compared to the raw materials had lowest reduction $(O, R$ and $U$ samples). Kruskal-Wallis test (Fisher F-test) analysis results also showed a significant correlation $(P<0.000)$ between $\mathrm{Na}$ changes with type and percentage of medium used in each treatment. Yadav reported that concentration of $\mathrm{Na}$ increased slightly in vermicomposting units of organic wastes in comparison to initial values (Yadav and Garg, 2011).

Ash in the final treatments compared to the raw material of vermicompost has increased. Highest amount of ash was in $F, P, Q, R, O, U, A, S$ samples and the lowest amount of ash were in the $D, E, K$ samples. Treatments that had the least amount of ash had the highest percentage of food in the context of raw materials. The result of Kruskal-Wallis test (Fisher F-test) analysis also showed a significant correlation $(P<0.013)$ between ash changes with type and percentage of medium used in each treatment. According to study of changes in biochemical properties of cow manure during processing by earthworms increase of ash reflecting mineralization of nitrogen and a rapid breakdown of carbon compounds by the earthworms (Atiyeh et al., 2000).

The status of organic materials of vermicompost treatments checked and results showed that the organic matter in the medium after three months have decreased. The results also showed that the average amount of organic materials in different medium were not the same. The result of Kruskal-Wallis test (Fisher F-test) analysis also showed a significant correlation $(P<0.002)$ between organic materials changes with type and percentage of medium used in each treatment. As stated in Table 3 kitchen waste contain the highest amount of organic materials from the raw materials and changes in the reduction of organic matter in samples was very low (L, K, $D, E$ samples). While the least amount of organic matter was observed in $F, P, Q, R, O, U, A, S$ samples and animal waste were formed the highest percentage of raw material of $F, P, Q, A, S$ samples and foliage were formed highest percentage of $R, O, U$ samples. The study of changes of carbon, nitrogen, phosphorous, and potassium content during storage of vermicomposts prepared from different substrates shows Total Organic carbon decreased after vermicomposting for all treatments except fly ash and the highest TOC content was recorded for cattle manure followed by paddy straw, MSW, and fly ash (Das et al., 2014).

The results pointed out the growth and reproduction of earthworms in the context of the medium that prepared of raw materials in different treatments. The largest number and greatest weight of worms in the medium of vermicompost treatments were observed in the $U$ and $Q$ samples after 90 days. The lowest number of worms was in the $D, E, K, L, M$ and $N$ treatments that did not exist animal waste in the medium of raw materials. The result of Kruskal-Wallis test (Fisher F-test) analysis showed however, the average number and weight of worms in different medium are not the same, but there is significant correlation $(P<0.000)$ between weight and the number of worms changes with type and percentage of medium used in each treatments. Evolution of the most substrate for the production of vermicomposting results showed animal manure medium had higher average than the plant waste in relation to the number and weight of worms (Hashemi et al., 2013), while study of effect of bulking materials on the growth and reproduction of the earthworm Eisenia Andrei in vermicomposting of sewage sludge, results showed the highest earthworm growth in the composition of sewage sludge and food waste and the least amount of growth in the food composition of sewage sludge and sawdust (Domínguez et al., 2000).

\section{Conclusion}

The medium has particular importance on the compost quality. So that any change in the composition due to changes in the presence or absence of macro and micronutrients can influence the composting process and worm reproduction. The study showed that food requires into pre-compost stage and aeration and higher levels of food are effective in quality of vermicompost treatments. The $U$ and $Q$ treatments that foliage and animal waste respectively were formed the highest percentage of raw material; to breed Eisenia fetida earthworms had more desirable conditions, that it would be given special attention on commercial terms to worm breeding. Analysis of vermicompost obtained from try types of organic substrates clearly indicates its ability to produce virmicompost with good quality.

\section{Acknowledgements}

The authors thank the faculty of health for the financial support of this research work.

\section{References}

Adi A.J. and Noor Z.M. (2009), Waste recycling: Utilization of coffee grounds and kitchen waste in vermicomposting, Bioresource Technology, 100, 1027-1030.

Atiyeh R.M., Dominguez J., Subler S. and Edwards C.A. (2000), Changes in biochemical properties of cow manureduring processing by earthworms (Eisenia andrei, Bouché) and the effects on seedling growth, Pedobiologia, 44, 709-724.

Bansal S. and Kapoor K.K. (2000), Vermicomposting of crop residues and cattle dung with Eisenia Foetida, Bioresource Technology, 73, 95-98.

Bremner J.M. and Mulvaney R.G. (1982), Nitrogen total. In: Page, A.L., Miller, R.H., Keeney, D.R. (Eds.), Methods of Soil Analysis. American Society of Agronomy, Madison, pp. 575-624.

Chen X., Geng Y. and Fujita T. (2010), An overview of municipal solid waste management in China, Waste Management, 30, 716-724.

Das D., Powell M., Bhattacharyya P. and Banik P. (2014), Changes of carbon, nitrogen, phosphorous, and potassium content 
during storage of vermicomposts prepared from different substrates, Environ Monit Assess, 186, 8827-8832.

Devi G.S., Karthiga A., Susila S. and Muthunarayanan V. (2012), Bioconversion of fruit waste into vermicompost by employing Eudrillus eugeniae and Eisenia foetida, International Journal of Plant, Animal and Environmental Sciences, 2(4), 245-252.

Domínguez J., Edwards C.A. and Webster M. (2000), Vermicomposting of sewage sludge: Effect of bulking materials on the growth and reproduction of the earthworm Eisenia Andrei, Journal Pedobiologia, 44, 24-32.

Elvira C., Sampedro L., Benitez E. and NogSales R. (1998), Vermicomposting of sludge by paper mill and dairy industrial with Eisenia Andrei. A pilot- scale study, Bioresource Technology, 63, 205-211.

Garg P., Gupta A. and Satya S. (2006), Vermicomposting of different types of waste using Eisenia foetida: A comparative study, Bioresource Technology, 97, 391-395.

Gheisari S., Danash S. and Torghabeh J.A. (2009), Vermicompost potentioal in recycling of herbage waste (a case report: Mashhad herbage vermicomposting), Natural resources and Agricultural sciences, 16(2).

Gupta R. and Garg V.K. (2008), Stabilization of primary sewage sludge during vermicomposting, Journal of Hazardous Materials, 153, 1023-1030.

Hartenstein R. and Hartenstein F. (1981), Physicochemical change effected in activaed sludge by the earthworm Eisenia Fetida, Journal Environmental, 10, 377-382.

Hashemi S.H.R., Beheshti A.M., Falahi Z., Safigholy S. and Nabavi A. (2013), Evolution of the most substrate for the production of vermicomposting. Paper presented at the 2th National Conference on the Sustainable Development of sustainable agriculture and the environment.

Huang K., Li F., Wei Y., Fu X. and Chen X. (2014), Effects of earthworms on physicochemical properties and microbial profiles during vermicomposting of fresh fruit and vegetable wastes, Bioresource Technology, 170, 45-52.

Hwairakpam M. and Bhargava R. (2009), Vermitechnology for sewage sludge recycling, Journal of Hazardous Materials, 161, 948-954.

Jicong H., Yanyun Q., Guangqing L. and Dong R. (2005), The Influence of Temperature, $\mathrm{pH}$ and $\mathrm{C} / \mathrm{N}$ Ratio on the Growth and Survival of Earthworms in Municipal Solid Waste, CIGR Ejournal, 7, 1-6.

Kaviraj and Sharma S. (2003), Municipal solid waste management through vermicomposting employing exotic and local species of earthworms, Bioresource Technology, 90, 169-173.

Lleó T., Albacete E., Barrena R., Font X., Artola A. and Sánchez A. (2013), Home and vermicomposting as sustainable options for biowaste management, Journal of Cleaner Production, 47, 70-76.

Majlessi M., Eslami A., Saleh H.N., Mirshafieean S. and Babaii S. (2012), Vermicomposting of food waste: assessing the stability and maturity, Journal of Environmental Health Science \& Engineering, 9(25), 1-6.

Malafaia G., da Costa Estrela D., Guimarãesc A.T.B., de Araújo F.G., Leandroe W.M. and de Lima Rodrigues A.S. (2015), Vermicomposting of different types of tanning sludge (liming and primary) mixed with cattle dung, Ecological Engineering, 85, 301-306.
Mitchell A. (1997), Production of Eisenia Fetida and vermicomposting from cattle manure, Soil Biol Biochem, 29(3/4), 763-766.

Ndgwa P., Thompson S. and Das K. (2000), Effect of stocking density and feeding rate on vermcomposting of Biosolids, Bioresource Technology, 71, 5-12.

Pokhrel D. and Viraraghavan T. (2005), Municipal solid waste management in Nepal: practices and challenges, Waste Management, 25, 555-562.

Pramanik P. (2010), Changes in microbial properties and nutrient dynamics in bagasse and coir during vermicomposting: Quantification of fungal biomass through ergosterol estimation in vermicompost, Waste Management, 30(5), 787-791.

Sharholy M., Ahmad K., Mahmood G. and Trivedi R.C. (2008), Municipal solid waste management in Indian cities - A review, Waste Management, 28, 459-467.

Singh J., Kaur A., Vig A.P. and Rup P.J. (2010), Role of Eisenia fetida in rapid recycling of nutrients from biosludge of beverage industry, Ecotoxicology and Environmental Safety, 73, 430-435.

Sufyan J., Hajeamalaki K., Sharyfi S. and Sharifi A. (2011), Use autum leaves was from the trees to grow any Eisenia fetida earthworms and vermicompost production of cheap organic, The 1th national conference on strategies for achieve sustainable development.

Suthar S. (2009), Vermicomposting of vegetable-market solid waste using Eisenia fetida: Impact of bulking material on earthworm growth and decomposition rate, Ecological Engineering, 35, 914-920.

Suthar S. and Singh S. (2008), Vermicomposting of domestic waste by using two epigeic earthworms, International Journal Environmental Science Technico, 5(1), 99-106.

Wani K.A., Mamta B. and Rao R.J. (2013), Bioconversion of garden waste, kitchen waste and cow dung into value-added products using earthworm Eisenia fetida, Saudi Journal of Biological Sciences, 20, 149-154.

Yadav A. and Garg V.K. (2011), Recycling of organic wastes by employing Eisenia fetida, Bioresource Technology, 102, 2874-2880. 